\title{
Risk Factors of High Burden Caregivers of Dementia Patients Institutionalized at Day-Care Centres
}

\author{
Ana Maseda ${ }^{1} \cdot$ Isabel González-Abraldes $^{1} \cdot$ Carmen de Labra $^{1} \cdot$ José $^{-}$ \\ Marey-López ${ }^{2}$ Alba Sánchez ${ }^{1}$ José C. Millán-Calenti ${ }^{1}$ \\ ${ }^{1}$ Gerontology Research Group, Faculty of Health Sciences, Universidade da Coruña, Campus de Oza, 15071 A Coruña, \\ Spain \\ ${ }^{2}$ Servicio de Neurología, Complejo Hospitalario Universitario de A Coruña, A Coruña, Spain
}

\begin{abstract}
We examined which variables are associated with day care centres utilization among caregivers of dementia patients. A cross-sectional analysis of sociodemographic variables, relationship with caring and psychological aspects was conducted in 58 informal caregivers with intense burden. $58.6 \%$ used day care assistance and $41.4 \%$ did not. The results showed the importance of the commitment between the caregiver and their family and friends. The use of day care services is independent of the age, gender, educational level, marital status, occupation and relationship with the patient. However, in the multivariate analysis the provision of help by families and friends predicted the use of day care assistance. The bivariate analysis showed a significant relationship between depressive symptoms and self-rated health with day care attendance. Screening the help provision from families and friends in caregivers of dementia patients with intense burden would be relevant to design interventions which delay their institutionalization and reduce costs.
\end{abstract}

Keywords Dementia . Caregiving . Elderly. Day care centre

\section{Introduction}

Dementia, one of the most common and serious disorders in later life, is associated with a progressive deterioration in higher cognitive functions including memory, thinking, orientation, comprehension, calculation, learning capacity, language, and judgment; and also with complicated consequences in ordinary life. This type of illness is a condition that affects many individuals over the world, increasing from 4 to 6 million new cases every year in the world (Ferri et al. 2005).

People with dementia generally require a high level of care and, in our society, informal caregivers such as spouses, daughters or sisters are the ones that provide this type of care (Rabins et al. 1982), playing a very important role in this process. Informal caregiving is an important factor not only in the prevention of long-term care placement but also in the prevention of adverse health outcomes (Kuzuya et al. 2011). If we consider the disease progression, at the very beginning dementia patients can stay at home almost without supervision, however, as the illness progresses, the level of support increases to end with the need of constant supervision. If people with dementia do not count with this type of support, they will not be able to remain at home as long as they wish. But caring someone with dementia is a very laborious task and caregivers of dementia patients manifest not only high levels of stress (Bertrand et al. 2006) but also high levels of neuroticism (González-Abraldes et al. 2013), depression (Gaugler et al. 2009; Herrera et al. 2013; Ramsay et al. 2012; Schulz et al. 1995; Smith et al. 2011) and anxiety symptoms (Cooper et al. 2007).

Dementia and cognitive impairment are two of the main causes for institutionalization in the elderly (Agüero-Torres et al. 2001), being the advanced age of patient (Andel et al. 2007; Dolinsky and Rosenwaike 1988; Dorenlot et al. 2005) or caregivers (Gaugler et al. 2003; He'bert et al. 2001; McCann et al. 2005), the quality of the prior husbandwife relationship (Ducharme et al. 2007), being male (Gaugler et al. 2003; Gilley et al. 2004; McCann et al. 2005), unmarried (Luck et al. 2008; Miller et al. 1999; Smith et al. 2000, 2001), living alone (Dolinsky and Rosenwaike 1988; Gaugler et al. 2003; Gilley et al. 2004), and low frequency of socializing with relatives and friends (Cohen-Mansfield and Wirtz 2007) other 
examples of predictors of institutionalization in patients with dementia.

Institutionalizing a patient with dementia is not an easy process, affecting caregiver's psychological and physical well-being (Sörensen et al. 2006). To delay the period of institutionalization, for example by taking the elderly to a day care centre, should be very positive for the emotional health of the caregiver and also predicts a protective effect before institutionalization takes place (Gaugler et al. 2005). Some functions of the adults' day care centres that should be mentioned are to procure care and friendship relations to elders who need them, to provide therapies to elders with dementia promoting their cognitive skills, and also to support caregivers to have some freedom to handle their own lives. Day care also seems to be of greatest benefit to caregivers, who experience less worry, overload and role captivity from the start (Mavall and Thorslund 2007).

In the literature it is easy to find articles dealing with predicting variables of institutionalization, however investigations dealing with the use of day care services (what is supposed to be the step before institutionalization) are scarce (Pinquart and Sörensen 2006). The objective of this article is to explore the variables that lead to this type of semi-internalization. Knowing the predictors of using day care centre services can be important if we need to develop interventions to delay institutionalization.

\section{Methods}

\section{Participants}

Participants were recruited from three different institutions, the Association of Relatives of Sufferers of Alzheimer's or Other Dementias, an Elderly Care Centre of the City of A Coruña (Spain), and patients from the Memory, Alzheimer and Other Dementia's Unit at the Complejo Hospitalario Universitario A Coruña (CHUAC), Spain. In the two first cases, questionnaire packets were sent to 109 caregivers. From the 41 questionnaires that were properly covered and returned, eight did not meet the inclusion criteria of severe burden of the caregiver. In other words, from the first two institutions we recruited 33 primary caregivers as participants of this study. Participants recruited from the CHUAC came from a sample of patients who attended regularly to clinical appointments. From all of them, 25 caregivers were included in the study since they met the criteria of severe burden. The total sample consisted of 58 caregivers with severe burden.

Each caregiver completed the self-administered assessment according to the recommendations given by a clinical psychologist with experience working with patients diagnosed with dementia and their informal caregivers.

The participants' relatives had been diagnosed with dementia by geriatricians and neurologists working in the institutions involved in the study. The inclusion criteria were as follows: Being the primary caregiver (if principally responsible for providing or coordinating the resources required by the person with dementia, such as housekeeping, financial help and shopping) of a person with dementia for at least the previous 6 months, irrespective of whether the caregiver lived with the person or not; providing the major source of unpaid elder care; the caregiving presenting a severe burden [score on the Zarit Burden Scale higher than 55 according to the reference values proposed by Martín et al. (1996)]; and fulfilling the proper informed consent form.

Caregivers were excluded if they did not possess the necessary skills to be assessed. Exclusion criteria for caregivers also included cognitive impairment, illiteracy or severely impaired vision and hearing.

\section{Material and Procedure}

The study protocol was approved by the Ethics Committee at the University of A Coruña and conformed to the principles embodied in the Declaration of Helsinki. Before the data collection, all participants were informed about the study and signed the corresponding Informed Consent.

Caregivers completed a demographic questionnaire that recorded information on caregiver age, gender, educational level (four categories: 0-4 years, 5-8 years, 9-12 years or high school diploma, or college experience or higher degree), marital status (married or not married), occupation (active or non-active), job modifications (yes or no), relationship with the patient before (four categories: warm, normal, distant and cold, or problematic) and during (three categories: has improved, remains the same, or 
has deteriorated) caring and help provided by family and friends (yes or no).

We measured perceived burden by using the Zarit Burden Interview (ZBI) (Zarit et al. 1980) adapted and validated for the Spanish language by Martín et al. (1996). This is a 22-item self-report instrument where caregivers rate the frequency with which they experience certain stressful aspects of caregiving on a scale from 1 (never) to 5 (almost always). Three cut-off scores were established:

No burden (22-46), slight burden (47-55), and severe burden (56-110).

Caregiver's depression symptoms were evaluated with the Spanish version (Sanz and Vázquez 1998) of the Beck Depression Inventory (BDI; Beck et al. 1961). BDI is a self-administered questionnaire comprising 21 items that evaluates a broad spectrum of depressive symptoms. For each item, the patient is required to select the answer that best reflects his or her present situation and the situation in the last week. The total score is obtained by adding the values of the presence and severity of a given symptom, as rated from 0 to 3 . The total scores can range from 0 to 63 points. The cut-off points usually accepted for scoring the intensity/severity of depression are the following: No depression: 0-9 points; mild depression: 10-18 points; moderate depression: 19-29 points and severe depression: C30 points (Beck et al. 1988).

Anxiety was assessed using the Spanish version (Seisdedos Cubero 2008) of the State-Trait Anxiety Inventory (STAI; Spielberger et al. 1970). The STAI is one of the instruments most frequently used for measuring anxiety in adults. Being a rapid self-report scale, it clearly differentiates between the temporary condition of "state anxiety" and the more general and long-standing quality of "trait anxiety". The instrument asks individuals to rate the symptoms of anxiety on a 4-point scale from 1 to 4 . The Spanish adaptation of this scale contains 40 items rated on a 4-point scale $(0-3)$ and is designed to measure the levels of state anxiety ( 20 items, situational and transient anxiety) and trait anxiety (20 items, dispositional and stable anxiety). The total scores vary from 0 to 60 , rather than the 20 to 80 in the original version.

Self-rated health (SRH) was measured with the question "In general, how would you rate your health?' Participants could give five possible answers: Very good, good, fair, poor and very poor.

Analysis

The software package IBM SPSS Statistics v.21.0 was used for data analysis. The results are expressed as percentages and mean \pm standard deviation. The Chi square test was used for examining associations between qualitative variables. A Pearson's correlation test was used between the continuous variable "anxiety" and the dependent variable "assist to a day care centre". A multiple logistic regression analysis was constructed to study the relationship between day care centre utilization among caregivers of dementia patients and the set of independent variables. Odds ratios (OR) were calculated for each covariable included in the model. Statistical significance was considered to be $\mathrm{p} \backslash 0.05$.

\section{Results}

The mean age of the 58 caregivers with severe burden was 56.3 years (range 28-82, SD 1.5), 51 (87.9 $\%$ ) were women, $77.6 \%$ were married and half of them (52.7\%) had from 9 to 12 years of educational level or a high school diploma. $26.3 \%$ of the subjects had the highest educational level and $21 \%$ of them had less than 9 years of schooling.

A bivariate analysis was carried out to show the sociodemographic variables, relationship with caring, and psychological-related characteristics considered in the study that could lead caregivers with severe burden to send their relatives to a day care centre. $58.6 \%$ of our sample attended a day care centre.

In our study, no association was found between the socio-demographic variables included and the condition day care attendance (DCA): age (distributed by age decades, 20-29 years, 30-39 years,..., 80-89 years), gender, educational level, marital status, occupation, and job lost. Half of caregivers not using DCA had between 40 and 59 years, while $64.7 \%$ of those using DCA were in the range from 50 to 69 years. Female gender predominated among caregivers in both cases, using DCA and not using DCA, 88.2 and $87.5 \%$ respectively. The caregivers were mostly married (73.5 and $83.3 \%$ for DCA and no-DCA respectively) and non-active subjects (58.8 and $58.3 \%$ for DCA and no-DCA respectively).

Considering relationship with caring, help provided by family and friends was the only variable 
related to the use of DCA; however, relationship with the patient before or during caring showed no significant differences. The most frequent relationships with the patient before caring were warm and normal (94.1 and $91.7 \%$ for DCA and no-DCA respectively), usually remaining the same relationship during caring (60.6 and $41.7 \%$ respectively). The results showed a statistically significant difference $(\mathrm{p}=$ 0.015), being those who received more help from family and friends the ones that use more this type of services $(71.4 \%)$. In relationship with psychological variables, both depressive symptoms and mental health of caregivers were significantly associated with DCA ( $p=0.05$, and $p=0.04$, respectively). In this sense, the percentage of caregivers with no depressive symptoms used more the option of DCA $(76.5 \%)$ in comparison with those caregivers with mild depressive symptoms (62.5\%), moderate symptoms (28.6 $\%$ ) or established depressive symptoms $(66.7 \%)$. In a similar way, those caregivers with good mental health are the ones that use the DCA the most $(80.0 \%)$, in comparison with those who report to have a fair mental health status $(59.4 \%)$ or a poor metal health $(30.0 \%)$. Finally, Pearson's correlation test showed that state anxiety was no significantly correlated with DCA, however, trait anxiety tended to be related to state anxiety $(\mathrm{p}=0.03)$.

The variables showing significant associations with day care assistance in the bivariate analysis were included as covariables in a multiple logistic regression analysis to assess the determinants of DCA. Only one out of four variables considered in the analysis turned out to be an important predictor of DCA. In this sense, help provided by family and friends was the single best predictor of DCA. Elderly demented people with caregivers scoring high on Zarit questionnaire and receiving help from family and friends were 4.06 times $(95 \%$ CI $1.186-13.941 ; p=0.026)$ more likely to attend a day care centre than those whose caregivers did not get this type of help.

\section{Discussion}

To date there is little scientific literature regarding the attendance to a day care centre between caregivers with severe burden of dementia patients, therefore, in this study we try to explore a field not so far investigated.

In an ever-aging society, the increase in dementia patients is becoming a social challenge. Optimization in the resources offered to caregivers is a determinant problem to solve. In this regard, day care is becoming a primary service delivery in countries with a high number of aged people, mainly because it is seen as an effective program to support caregivers and because it is considered a previous step before institutionalization. Our results showed that from the measures we considered, only the provision of help from family and friends significantly predicted the use of day care services. This is consistent with the fact that caregivers' subjective wellbeing improves when they receive support, even when this support is based on a software application (Millán-Calenti et al. 2000), as this would delay institutionalization. In our investigation we found that the utilization of a day care centre was not associated with the age of the caregiver, and this agrees with some other studies (Douglass and Visconti 1998; Hébert et al. 2001; Montoro et al. 2003) but not with others (van Exel et al. 2006). Coinciding with these last authors, our study also shows that neither the level of education nor the variable gender had any influence in the utilization of day care facilities. Considering specifically the variable level of education, it could be easily presumed that level of education is related to incomes, what would imply fewer problems to join a day care centre program. However, because of the problematic economic recession we are suffering, it seems logical not to find so many differences regarding this variable. It is also interesting to note that our study sample was mainly integrated by females. Regarding this variable, in literature we found that men and women provide different patterns of assistance, patterns consistent with a gender-based division of labour (Stoller 1990), having women more frequent, intensive, affective and psychological involvement in the caregiver role (Parks and Pilisuk 1991) than men.

Considering marital status, our study does not find any difference between this variable and day care centre attendance. However, a literature review shows that not only spouses generally suffer more stress than other relatives when caring a spouse/husband (Baumgarten et al. 1992; Grafström et al. 1992) but also they are more engaged in the caregiving relationship, implying that married people are normally institutionalized later than unmarried people (Colerick and George 1986; Lieberman and Kramer 1991; Scott et al. 1997). The different results found in our study compared to others could be reflecting the fact that DCA is a previous step before institutionalization, being the level of behavioural and functional dis- 
turbance of our sample not so impaired to prevent them to take care of themselves, and therefore delaying this type of semi-institutionalization.

Regarding the provision of help by family and friends, it is well known the fact that family caregivers play a critical role in keeping patients with dementia living in the community (Alzheimer's Association 2008). Caring family members with dementia needs adequate forms of relief in order to delay institutionalization, and as our data suggests, being in contact and receiving help from family and friends is a very good option. Our findings, although in line with other studies (Mittelman et al. 2006) do not continue the line of others (Joling et al. 2012) which found that regular family meetings for caregivers of dementia patients did not delay patient institutionalization.

Depressive symptoms in caregivers have been associated with increased risk of institutionalization (Cohen-Mansfield and Wirtz 2011;He'bert et al. 2001), increased social support and healthcare services (Herrera et al. 2013). Our study, although in line with this, also shows that caregivers without depressive symptoms are the ones who use the most the day care services. An explanation to this fact is that day care interventions help caregivers to effectively reduce depressive symptoms, increasing general subjective well-being (Sörensen et al. 2002). Providing care to a person with dementia implies a meaningful risk for adverse psychiatric outcomes (Pinquart and Sörensen 2003; Schulz and Martire 2004), however, and in agreement with the previous paragraph, caregivers with the best signs of metal health are the ones using day care centres services. This could be in part because day care services offer respite programs to caregivers and therapies aimed to enable older people to remain active in the community, gaining skills to be independent (Garcés et al. 2009). Overall social support is one of the most powerful predictors of caregiver depressive symptomatology (Song et al. 1997). Another interesting finding is that anxiety, both state and trait, does not correlate with DCA. We should add that we looked specifically at dementia patients of Spain, while others studies took place in other countries with a very different situation. In this regard, while in other countries a great number of caregivers are professionals paid for their job, in Spain, as well as in other southern European countries (such as Greece and Italy), most informal caregivers spend time providing care to a family member without receiving any type of reward (Toribio-Díaz et al. 2013).

Our study has several strengths as well as a number of limitations. We considered only caregivers with intense level of burden, and although it does not allow us to generalize our findings to other type of caregivers, we accurately delimited the characteristics associated with this group. Also, our sample was recruited in terms of intense caregiving, in contrast with previous studies that recruited patients from the onset of disease or cognitive impairment, what provides originality to our study. Also, DCA of dementia people offers the possibility of being near a professional, what may delay institutionalization and help the person to remain active in the community. An important factor in this study is that caregivers were mainly recruited via health care facilities and not through community-based epidemiological interviews as in most studies of informal caregivers of demented elderly people. On the other hand, a limitation of our study was that caregiving burden was only measured at baseline, which leads to the bias that it is not possible to difference between caregivers with severe burden for long periods of time from those who just entered in this state.

In summary, help provided by family and friends is a very important preventive avenue to delay institutionalization of people with dementia. This fact would help to reduce, from a health-policy point of view, the costs engaged in these types of services. Also, we consider that the variable help provided by family and friends should be included in future models of semi-institutionalization process.

Conflict of interest The authors declare that there are no known conflicts of interest. All authors certify (a) that they accept responsibility for the conduct of the study and for the analysis and interpretation of the data, (b) that they helped write the manuscript and agree with the decisions about it, (c) that they meet the definition of an author as stated by the International Committee of Medical Journal Editors, and (d) that they have seen and approved the final manuscript. 


\section{References}

Agüero-Torres, H., von Strauss, E., Viitanen, M., Winblad, B., \& Fratiglioni, L. (2001). Institutionalization in the elderly: The role of chronic diseases and dementia. Cross-sectional and longitudinal data from a population-based study. Journal of Clinical Epidemiology, 54, 795-801.

Andel, R., Hyer, K., \& Slack, A. (2007). Risk factors for nursing home placement in older adults with and without dementia. Journal of Aging and Health, 19, 213-228.

Association, Alzheimer's. (2008). 2008 Alzheimer's disease facts and figures. Alzheimers \& Dementia, 4, 110-133.

Baumgarten, M., Battista, R. N., Infante-Rivard, C., Hanley, J. A., Becker, R., \& Gauthier, S. (1992). The psychological and physical health of family members caring for an elderly person with dementia. Journal of Clinical Epidemiology, 45, 61-70.

Beck, A. T., Steer, R. A., \& Garbin, M. G. (1988). Psychometric properties of the Beck Depression Inventory. Twenty-five years of evaluation. Clinical Psychology Review, 8, 77-100.

Beck, A. T., Ward, C. H., Mendelson, M., Mock, J., \& Erbaugh, J. (1961). An inventory for measuring depression. Archives of General Psychiatry, 4, 561-571. doi:10.1001/archpsyc.1961. 01710120031004.

Bertrand, R. M., Fredman, L., \& Saczynski, J. (2006). Are all caregivers created equal? Stress in caregivers to adults with and without dementia. Journal of Aging and Health, 18, 534-551.

Cohen-Mansfield, J., \& Wirtz, P. W. (2007). Characteristics of adult day care participants who enter a nursing home. Psychological Aging, 22, 354-360.

Cohen-Mansfield, J., \& Wirtz, P. W. (2011). Predictors of entry to the nursing home: Does length of follow-up matter? Archives of Gerontology and Geriatrics, 53, 309-315.

Colerick, E. J., \& George, L. K. (1986). Predictors of institutionalization among caregivers of patients with Alzheimer's disease. Journal of the American Geriatrics Society, 34, 493-498.

Cooper, C., Balamurali, T. B., \& Livingston, G. (2007). A systematic review of the prevalence and covariates of anxiety in caregivers of people with dementia. International Psychogeriatrics, 19, 175-195.

Dolinsky, A. L., \& Rosenwaike, I. (1988). The role of demographic factors in the institutionalization of the elderly. Research on Aging, 10, 235-257.

Dorenlot, P., Harboun, M., Bige, V., Henrard, J. C., \& Ankri, J. (2005). Major depression as a risk factor for early institutionalization of dementia patients living in the community. International Journal of Geriatric Psychiatry, 20, 471-478.

Douglass, C., \& Visconti, C. (1998). Factors influencing the use of adult day care by individuals with Alzheimer's disease: A multivariate examination of the California Alzheimer's Disease Diagnostic and Treatment Center Program. Home Health Care Services Quarterly, 17, 53-69.

Ducharme, F., Levesque, L., Lachance, L., Gangbe, M., Zarit, S. H., Vezina, J., et al. (2007). Older husbands as caregivers: Factors associated with health and the intention to end home caregiving. Research on Aging, 29, 3-31.

Ferri, C. P., Prince, M., Brayne, C., Brodaty, H., Fratiglioni, L., Ganguli, M., et al. (2005). Global prevalence of dementia: A Delphi consensus study. Lancet, 6, 2112-2117.

Garcés, J., Carretero, S., Ródenas, F., \& Sanjosé, V. (2009). Variables related to the informal caregivers' burden of dependent senior citizens in Spain. Archives of Gerontology and Geriatrics, 48, 372-379.

Gaugler, J. E., Kane, R. L., Kane, R. A., Clay, T., \& Newcomer, R. (2003). Caregiving and institutionalization of cognitively impaired older people: Utilizing dynamic predictors of change. The Gerontologist, 43, 219-229.

Gaugler, J., Kane, R. L., Kane, R. A., \& Newcomer, R. (2005). Early community-based service utilization and its effects on institutionalization in dementia caregiving. The Gerontologist, 45, 177-185.

Gaugler, J. E., Mittelman, M. S., Hepburn, K., \& Newcomer, R. (2009). Predictors of change in caregiver burden and depressive symptoms following nursing home admission. Psychological Aging, 24, 385-396.

Gilley, D. W., Bienias, J. L., Wilson, R. S., Bennett, D. A., Beck, T. L., \& Evans, D. A. (2004). Influence of behavioral symptoms on rates of institutionalization for persons with Alzheimer's disease. Psychological Medicine, 34, 1129-1135.

González-Abraldes, I., Millán-Calenti, J. C., Lorenzo-López, L., \& Maseda, A. (2013). The influence of neuroticism and extraversion on the perceived burden of dementia caregivers: An exploratory study. Archives of Gerontology and Geriatrics, 56, 91-95.

Grafström, M., Fratiglioni, L., Sandman, P. O., \& Winblad, B. (1992). Health and social consequences for relatives of demented and non-demented elderly. A population-based study. Journal of Clinical Epidemiology, 45, 861-870.

Hébert, R., Dubois, M. F., Wolfson, C., Chambers, L., \& Cohen, C. (2001). Factors associated with long-term institutionalization of older people with dementia: Data from the Canadian study of health and aging. The Journals of Gerontology Series A- Biological Sciences and Medical Sciences, 56, 693-699.

Herrera, A. P., Mendez-Luck, C. A., Crist, J. D., Smith, M. L., Warre, R., Ory, M. G., et al. (2013). Psychosocial and cognitive health differences by caregiver status among older Mexican Americans. Community Mental Health Journal, 49, 61-72.

Joling, K. J., van Marwijk, H. W. J., van der Horst, H. E., Scheltens, P., van de Ven, P. M., Appels, B. A., et al. (2012). Effectiveness of family meetings for family caregivers on delaying time to nursing home placement of dementia patients: A randomized trial. PLoS One, 7, e42145.

Kuzuya, M., Hasegawa, J., Hirakawa, Y., Enoki, H., Izawa, S., Hirose, T., et al. (2011). Impact of informal care levels on discontinuation of living at home in community-dwelling dependent elderly using various community-based services. Archives of Gerontology and Geriatrics, 52, 127-132. 
Lieberman, M. A., \& Kramer, J. H. (1991). Factors affecting decisions to institutionalize demented elderly. The Gerontologist, 31, 371-374.

Luck, T., Luppa, M., Weber, S., Matschinger, H., Glaesmer, H., Konig, H. H., et al. (2008). Time until institutionalization in incident dementia cases-results of the Leipzig Longitudinal Study of the Aged (LEILA 75?). Neuroepidemiology, 31, 100-108.

Martín, M., Salvado, I., Nadal, S., Miji, L. C., Rico, J. M., Lanz, P., et al. (1996). Adaptación para nuestro medio de la escala de sobrecarga del cuidador (Caregiver Burden Interview) de Zarit [Adaptation to our environment of the Zarit Caregiver Burden interview]. Revista de Gerontología, 6, 338-346.

Mavall, L., \& Thorslund, M. (2007). Does day care also provide care for the caregiver? Archives of Gerontology and Geriatrics, 45, 137-150.

McCann, J. J., Hebert, L. E., Li, Y., Wolinsky, F. D., Gilley, D. W., Aggarwal, N. T., et al. (2005). The effect of adult day care services on time to nursing home placement in older adults with Alzheimer's disease. The Gerontologist, $45,754-763$.

Millán-Calenti, J. C., Gandoy-Crego, M., Antelo-Martelo, M., López-Martinez, M., Riveiro-López, M. P., \& Mayán-Santos, J. M. (2000). Helping the family carers of Alzheimer's patients: From theory...to practice. A preliminary study. Archives of Gerontology and Geriatrics, 30, 131-138.

Miller, S. C., Prohaska, T. R., \& Furner, S. E. (1999). Nursing home admission for African Americans with Alzheimer's disease. The Journals of Gerontology Series A-Biological Sciences and Medical Sciences, 54, 365-369.

Mittelman, M. S., Haley, W. E., Clay, O. J., \& Roth, D. L. (2006). Improving caregiver well-being delays nursing home placement of patients with Alzheimer disease. Neurology, 67, 1592-1599.

Montoro, J., Kosloski, K., \& Montgomery, R. (2003). Evaluating a practice-oriented service model to increase the use of respite services among minorities and rural caregivers. The Gerontologist, 43, 916-924.

Parks, S. H., \& Pilisuk, M. (1991). Caregiver burden: Gender and the psychological costs of caregiving. American Journal of Orthopsychiatry, 61, 501-509.

Pinquart, M., \& Sörensen, S. (2003). Differences between caregivers and noncaregivers in psychological health and physical health: A meta-analysis. Psychology and Aging, 18, 250-267.

Pinquart, M., \& Sörensen, S. (2006). Helping caregivers of persons with dementia: Which interventions work and how large are their effects? International Psychogeriatrics, 18, 577-595.

Rabins, P. V., Mace, N. L., \& Lucas, M. J. (1982). The impact of dementia on the family. Journal of the American Medical Association, 248, 333-335.

Ramsay, C. E., Walker, E. R., Ramsay, R., Compton, M. T., \& Thompson, N. (2012). An exploration of perceptions of possible depression prevention services for caregivers of elderly or chronically ill adults in rural Georgia. Community Mental Health Journal, 48, 167-178.

Sanz, J., \& Vázquez, C. (1998). Fiabilidad, validez y datos normativos del inventario para la depresión de Beck [Reliability, validity, and normative data of the Beck Depression Inventory]. Psicothema, 10, 303-318.

Schulz, R., \& Martire, L. M. (2004). Family caregiving of persons with dementia: Prevalence, health effects, and support strategies. American Journal of Geriatric Psychiatry, 12, 240-249.

Schulz, R., O’Brien, A. T., Bookwala, J., \& Fleissner, K. (1995). Psychiatric and physical morbidity effects of dementia caregiving: Prevalence, correlates, and causes. The Gerontologist, 35, 771-791.

Scott, W. K., Edwards, K. B., Davis, D. R., Cornman, C. B., \& Macera, C. A. (1997). Risk of institutionalization among community long-term clients with dementia. The Gerontologist, 37, 46-51.

Seisdedos Cubero, N. (2008). Cuestionario de ansiedad estado-rasgo: Manual [STAI, manual for the State-Trait Anxiety Inventory] (7th ed.). Madrid: TEA.

Smith, G. E., Kokmen, E., \& O'Brien, P. C. (2000). Risk factors for nursing home placement in a population-based dementia cohort. Journal of the American Geriatrics Society, 48, 519-525.

Smith, G. E., O’Brien, P. C., Ivnik, R. J., Kokmen, E., \& Tangalos, E. G. (2001). Prospective analysis of risk factors for nursing home placement of dementia patients. Neurology, 57, 1467-1473.

Smith, G. R., Williamson, G. M., Miller, L. S., \& Schulz, R. (2011). Depression and quality of informal care: A longitudinal investigation of caregiving stressors. Psychological Aging, 26, 584-591.

Song, L. Y., Biegel, D. E., \& Milligan, S. E. (1997). Predictors of depressive symptomatology among lower social class caregivers of persons with chronic mental illness. Community Mental Health Journal, 33, 269-286.

Sörensen, S., Duberstein, P., Gill, D., \& Pinquart, M. (2006). Dementia care: Mental health effects, intervention strategies, and clinical implications. Lancet Neurology, 5, 961-973.

Sörensen, S., Pinquart, M., \& Duberstein, P. (2002). How effective are interventions with caregivers? An updated meta-analysis. The Gerontologist, 42, 356-372.

Spielberger, C. D., Gorsuch, R. L., \& Lushene, R. E. (1970). STAI, manual for the State-Trait Anxiety Inventory (self-evaluation questionnaire). Palo Alto, CA: Consulting Psychologist.

Stoller, E. P. (1990). Males as helpers: The role of sons, relatives, and friends. The Gerontologist, 30, 228-235.

Toribio-Díaz, M. E., Medrano-Martínez, V., Moló-Jordá, J. M., \& Beltrán-Blasco, I. (2013). Red de cuidadores informales de los pacientes con demencia en la provincia de Alicante, descripción de sus características [Characteristics of informal caregivers of 194-208. patients with dementia in Alicante province]. Neurologia, 28, 
van Exel, J., Morée, M., Koopmanschap, M., Goedheijt, T. S., Respite care-An explorative study of demand and use in Dutch informal caregivers. Health Policy, 78,194-208.

Zarit, S. H., Reever, K. E., \& Bach-Peterson, J. (1980). Relatives of the impaired elderly: Correlates of feelings of burden. The Gerontologist, 20, 649-655. 